\title{
O estágio de docência no processo de construção da identidade profissional de pós-graduandos
}

\author{
Maria da Cruz Santos Guimarãesi $\mathbb{D}$ \\ Universidade Estadual do Ceará, Fortaleza, CE, Brasil
}

Elisangela André da Silva Costai ${ }^{\mathrm{i}}$

Universidade da Integração Internacional da Lusofonia Afro-Brasileira, Redenção, CE, Brasil

\begin{abstract}
Resumo
O estudo visou compreender as potencialidades do estágio de docência no processo de construção da identidade profissional de pós-graduandos em Educação a partir de pesquisa de campo, com abordagem qualitativa. Os principais aportes teóricos utilizados foram Cavalcante (2014), Melo (2018), Pimenta e Anastasiou (2008), sobre formação de professores de ensino superior, e Costa (2014), Nóvoa $(1992,2017)$ e Pimenta e Lima (2017), estabelecendo relações entre estágio, docência e construção da identidade profissional. Como estratégia de aproximação com a realidade, sete pós-graduandos stricto sensu em Educação responderam ao questionário via Google Forms. Concluiu-se que o estágio permite o conhecimento das especificidades que marcam os processos de ensino e aprendizagem no ensino superior, constituindo-se em espaço propício de formação didático-pedagógico para pós-graduandos, desde que desenvolvido numa perspectiva crítico-reflexiva e colaborativa entre os sujeitos envolvidos no processo de ensinar e de aprender a profissão.
\end{abstract}

\section{Palavras-chave}

Estágio; Docência; Formação de Professores; Identidade Profissional; Ensino Superior.

\section{The teaching internship in the process of building}

the professional identity of graduate students

\begin{abstract}
The study aimed to understand the potential of the teaching internship in the process of building the professional identity of postgraduate students in Education through field research, with a qualitative approach. The main theoretical contributions used were Cavalcante (2014), Melo (2018), Pimenta and Anastasiou (2008), on higher education teacher formation and Costa (2014), Nóvoa (1992, 2017) and Pimenta and Lima (2017), establishing relationships between internship, teaching and construction of professional identity. As a strategy to get closer to reality, seven stricto sensu postgraduate students in Education answered questionnaires via google forms. It is possible to conclude that the internship allows the knowledge of the specificities that mark the teaching and learning processes in Higher Education, constituting a conducive space for didactic-pedagogical formation for postgraduate students, since it is developed in a critical-reflective and collaborative perspective between the subjects involved in the process of teaching and learning the profession.
\end{abstract}

\section{Keywords}

Internship; Teaching; Teacher Formation; Professional Identity; University Education. 


\title{
La pasantía docente en el proceso de construcción
}

\author{
de la identidad profesional de los estudiantes de posgrado
}

\begin{abstract}
Resumen
El estudio tuvo como objetivo comprender el potencial de la pasantía docente en el proceso de construcción de la identidad profesional de los estudiantes de posgrado en educación, através de la investigación de campo, con un enfoque cualitativo. Las principales aportaciones teóricas utilizadas fueron Cavalcante (2014), Melo (2018), Pimenta e Anastasiou (2008), sobre la formación docente de educación superior, y Costa (2014), Nóvoa (1992, 2017) y Pimenta y Lima (2017), estableciendo relaciones entre prácticas, docencia y construcción de identidad profesional. Como estrategia para acercarse a la realidad, siete estudiantes de posgrado en educación stricto sensu respondieron cuestionarios mediante el uso del Google Forms. Se concluyó que la pasantía permite el conocimiento de las especificidades que marcan los procesos de enseñanza y aprendizaje en la educación superior, constituyendo un espacio propicio para la formación didáctico-pedagógica de los estudiantes de posgrado, ya que se desarrolla en una perspectiva crítico-reflexiva y colaborativa entre los sujetos involucrados en el proceso de enseñanza y aprendizaje de la profesión.
\end{abstract}

\section{Palabras clave}

Prácticas; Enseñanza; Formación De Profesores; Identidad Profesional; Enseñanza Superior.

\section{Introdução}

O presente estudo emergiu no âmbito de um programa de pós-graduação stricto sensu em Educação, em que participamos de discussões em torno da formação de professores para a atuação no ensino superior, discussões estas que nos impulsionaram a questionar os caminhos formativos e profissionais que envolvem o processo de construção da identidade docente nos diferentes espaços e contextos.

Quando olhamos para a realidade brasileira, identificamos dois elementos basilares que nos inquietaram: o primeiro relaciona-se às especificidades formativas da pós-graduação, historicamente marcada pela pesquisa e voltada à formação de pesquisadores; e o segundo diz respeito à prerrogativa legal de a pós-graduação stricto sensu constituir-se como espaço prioritário de preparação para o magistério no ensino superior conforme a Lei de Diretrizes e Bases da Educação Nacional (LDBEN) no 9.394/1996.

Diferentes estudos apresentam a existência de um descompasso entre a tradição histórica e as orientações normativas que acaba por gerar um distanciamento da 
organização curricular dos mestrados e doutorados dos debates relacionados à docência. Nesse sentido, a disciplina Estágio de Docência, ao mesmo tempo que adquire uma importância singular no processo de formação de professores para o nível superior, não se afirma como prioridade, uma vez que é comum que essa disciplina seja obrigatória apenas para os estudantes bolsistas que não dispõem de experiência profissional nesse nível de ensino de acordo com a Portaria ํo 76, de 14 de abril de 2010, da Coordenação de Aperfeiçoamento de Pessoal de Nível Superior (Capes).

Considerando o avanço de uma instituição pública de ensino superior localizada no estado do Ceará, que, firmando seu compromisso com a formação de professores, definiu como obrigatória a disciplina supramencionada para todos os estudantes, bolsistas e não bolsistas, que não dispõem de tal experiência, propusemos o desenvolvimento do presente estudo, que tem como objetivo compreender as potencialidades do estágio de docência no processo de construção da identidade profissional de pós-graduandos stricto sensu em Educação. Para a aproximação com a realidade, recorremos ao diálogo com a literatura, a partir das categorias formação de professores e educação superior, e ainda à aplicação de questionários, para acessarmos as experiências de pós-graduandos em Educação quanto a esse componente de sua formação.

Dentre as referências que sustentaram a análise da realidade, destacamos os estudos desenvolvidos por Cavalcante (2014), Costa (2014), Melo (2018), Pimenta e Anastasiou (2008) e Pimenta e Lima (2017). Os resultados apontam que a disciplina Estágio de Docência pode desempenhar um importante papel no processo de construção da identidade profissional de pós-graduandos, propiciando-Ihes férteis reflexões sobre a aprendizagem da docência universitária no contexto das licenciaturas e bacharelados, estimulando a ressignificação de experiências e a construção de novos conhecimentos no campo da Pedagogia Universitária.

\section{Metodologia}

O estudo apresenta uma abordagem qualitativa e constituiu-se em duas etapas. A primeira consistiu em um levantamento da literatura sobre a formação de professores de ensino superior. Já a segunda consistiu em pesquisa junto a estudantes do Programa

Educ. Form., Fortaleza, v. 7, n. 1, e4853, jan./abr. 2022

DOI: https://doi.org/10.25053/redufor.v7i1.4853

https://revistas.uece.br/index.php/redufor/index 
de Pós-Graduação em Educação (PPGE) da Universidade Estadual do Ceará (UECE) em torno de suas experiências como estagiários no âmbito do referido programa.

$\mathrm{Na}$ condução do estudo, foram considerados os princípios éticos difundidos em documentos por associações que subsidiam a pesquisa com seres humanos. Nesse sentido, os participantes foram contatados no próprio espaço da instituição, tomando como critérios de inclusão: pertencer à turma de mestrado/doutorado 2019; ter realizado 0 estágio de docência no âmbito da pós-graduação da UECE; e aceitar participar do estudo. A adesão voluntária foi declarada por meio do preenchimento do Termo de Consentimento Livre e Esclarecido (TCLE). A partir do aceite, foi elaborado um questionário através do Google Forms e enviado para os sujeitos por e-mail. No total, oito pós-graduandos aceitaram participar do estudo e responderam ao questionário, sendo sete estudantes do mestrado e um do doutorado. No entanto, devido à estudante do doutorado ter apresentado três anos de experiência na docência universitária, preferiram-se considerar nas análises apenas as respostas referentes aos estudantes do mestrado.

O questionário enviado aos participantes era composto por 11 questões, sendo que seis (entre as quais abertas e fechadas) versavam sobre o perfil dos sujeitos, através dos itens: sexo, faixa etária, curso em andamento na pós-graduação (mestrado ou doutorado), formação (inicial e continuada), experiência como docente do ensino básico (quantos anos e nível de ensino); as demais questões versavam sobre as experiências com o estágio de docência, sendo todas abertas, utilizando-se na apresentação dos resultados e discussão os seguintes itens: "Você considera que o estágio de docência da pós-graduação contribuiu para o seu processo de aprendizagem da docência universitária? Se sim, comente a experiência e as aprendizagens constituídas"; "Quais dificuldades você enfrentou?"; e "A partir dessa experiência, responda qual é (ou quais são) o(s) maior(es) desafio(s) de ser professor universitário? Justifique".

Para a análise das respostas dos questionários, foi utilizada a técnica de análise de conteúdo (BARDIN, 2011). Nesse processo, os dados obtidos foram tratados de forma a fornecer indicadores para a compreensão do objetivo da pesquisa. Inicialmente se realizou o recorte do material em unidades de registro (palavras, frases, parágrafos) que fossem comparáveis de acordo com o conteúdo semântico. A partir do agrupamento das unidades de registro, foram estabelecendo-se categorias com vistas ao processo de inferência e interpretação, buscando o diálogo com o referencial teórico. Para manter o 
anonimato, utilizou-se a seguinte codificação: "M" para mestrado, seguido das letras "A" à "G", para distinguir os sujeitos.

\section{Formação de professores para a educação superior: especificidades e lacunas}

A literatura sobre a formação de professores para a educação superior aponta para uma problemática relacionada à legislação que diz respeito à superficialidade com que são tratados alguns aspectos concernentes à docência nesse nível de ensino, como as finalidades e as especificidades que marcam o exercício profissional docente na universidade. Quanto às especificidades que marcam o ensino superior, a vigente LDBEN explicita, no artigo 43, as seguintes finalidades:

\footnotetext{
I - estimular a criação cultural e o desenvolvimento do espírito científico e do pensamento reflexivo; II - formar diplomados nas diferentes áreas de conhecimento, aptos para a inserção em setores profissionais e para a participação no desenvolvimento da sociedade brasileira, e colaborar na sua formação contínua [...].
}

Para a atuação docente no ensino superior, a LDBEN legisla, no artigo 66, que "[...] a preparação para o exercício do magistério superior far-se-á em nível de pós-graduação, prioritariamente em programas de mestrado e doutorado". No entanto, há um ponto questionável quanto à formação específica para os processos de ensinar e aprender essa profissão, em virtude das características desses cursos, que adotam a pesquisa como eixo da formação, sem garantir uma formação didático-pedagógica para o exercício da docência (MELO, 2018; PIMENTA; ANASTASIOU, 2008).

Pimenta e Anastasiou (2008), discorrendo sobre a docência no ensino superior e a construção da identidade do professor universitário, apontam que em muitas instituições, apesar da experiência e do conhecimento das diferentes áreas pelos profissionais que nelas atuam, é perceptível o despreparo ou mesmo o desconhecimento destes em relação ao processo de ensino e aprendizagem. As referidas autoras, em uma análise do panorama internacional, constatam uma preocupação quanto à formação e ao desenvolvimento profissional de professores universitários, assim como as inovações no campo da Didática, o que se explica pela expansão da educação superior e, assim, da própria profissão (PIMENTA; ANASTASIOU, 2008). Desse modo, percebe-se um movimento de pesquisadores preocupados com a formação do docente do ensino superior, considerando tanto o movimento formativo que acontece nos programas de 
pós-graduação quanto a continuidade desses docentes nas instituições onde já atuam profissionalmente.

Cavalcante (2014) corrobora a compreensão da necessidade de pensar nos processos de formação docente para a atuação na educação superior, destacando os contributos da Pedagogia Universitária, campo de conhecimento em construção que oferece um arcabouço consistente de contributos teóricos e metodológicos para a formação do professor.

Refletindo sobre essa temática, Melo (2018) denuncia a ausência da pedagogia na universidade e, a partir da discussão sobre a Pedagogia Universitária, indica que se faz necessária uma revisão da cultura da universidade, de modo que se reflita sobre ela e se explicitem as concepções de educação, didática, formação e desenvolvimento profissional docente que orientem os processos de formação vividos não só pelos discentes, mas pelos próprios docentes. Compreende-se, a partir dos contributos da autora, que os diferentes elementos presentes nessa problemática podem ser atribuídos, principalmente, à omissão da legislação, que não prevê um sistema de formação para esse nível de ensino. Desse modo, a "preparação" fica a cargo de atividades como as poucas disciplinas que podem constar nos currículos dos mestrados e doutorados e ainda o estágio de docência, orientados não raras vezes por professores que também não dispõem de formação pedagógica sistematizada (MELO, 2018).

O conjunto de autores mencionados colabora para a compreensão dos limites da formação dos professores universitários, ressaltando o fato de que a pós-graduação stricto sensu historicamente constitui-se como espaço de valorização da pesquisa, com vistas ao domínio dos conhecimentos a ela relacionados, não sendo possível perceber o mesmo compromisso com o campo da docência e com os saberes pedagógicos.

\section{A pós-graduação stricto sensu em Educação da UECE e o estágio de docência como componente da formação}

O PPGE da UECE do Centro de Educação localiza-se em Fortaleza, Ceará. Adotando a formação de professores como área de concentração, o programa dispõe de conceito Capes 5 e oferece cursos de mestrado e doutorado em Educação (PPGE/UECE, 2020). Nesse programa, o estágio de docência compõe-se como 
componente curricular obrigatório na formação dos estudantes, a menos que se comprovem experiência de, no mínimo, um ano como docente de ensino superior, conforme a Resolução nº 821/2011 do Conselho Universitário (Consu), de 19 de dezembro de 2011, que regulamenta o estágio de docência na instituição. Essa resolução define que as experiências são constituídas conforme a relação estabelecida com a disciplina ministrada pelo orientador de dissertação/tese na graduação, ou por ele recomendado, durante um semestre para mestrandos e dois semestres para doutorandos, com uma carga horária máxima de quatro horas semanais e 68 horas semestrais (UECE, 2011). No artigo 5ำ são previstas atribuições aos pós-graduandos no estágio, sendo:

\begin{abstract}
1) Colaborar com o professor responsável pela disciplina, conforme plano de atividades previamente elaborado pelo docente, em conjunto com o estagiário: a) em atividades complementares necessárias ao bom andamento da disciplina: seminários, divulgação de pesquisa ou outras atividades que objetivem acréscimos aos conhecimentos trabalhados em aula; b) na confecção e apresentação de material didático e busca de bibliografia necessária ao bom funcionamento da aula; c) no atendimento especial em relação à orientação de trabalhos de alunos regularmente matriculados na disciplina; d) em atividades de pesquisa relacionadas diretamente à investigação do cotidiano da disciplina em que é realizado o estágio.
\end{abstract}

Desse modo, conforme as características apresentadas sobre o estágio de docência da UECE, este pode se configurar em processo de aprendizagens em torno do ser professor de ensino superior, conforme ainda as reflexões que são tecidas no tópico a seguir sobre o estágio e a construção da identidade profissional docente.

\title{
4.1 Reflexões sobre o estágio na construção da identidade profissional docente
}

A identidade pode ser compreendida como movimento, como processo de construção dinâmico e mutável, protagonizado por sujeitos situados historicamente. Quando estabelecemos a relação dessa compreensão com o movimento ocorrido durante a formação de professores, no qual se fortalece a constituição da identidade profissional docente, verificamos o diálogo entre sujeito e contexto, a partir da significação social da profissão (PIMENTA, 2005), e ainda a construção de modos distintos de vivência da profissão (NÓVOA, 1992). 
A partir das reflexões sobre as relações indissociáveis entre o indivíduo, o contexto e o coletivo profissional no processo de construção identitária do docente, entendemos que se faz necessária a leitura crítica dos elementos teóricos e práticos presentes na formação e no exercício profissional docente.

Segundo Nóvoa (2017, p. 1116):

A formação deve funcionar em alternância, com momentos de forte pendor teórico nas disciplinas e nas ciências da educação, seguidos de momentos de trabalho nas escolas, durante os quais se levantam novos problemas a serem estudados através da reflexão e da pesquisa.

Pimenta e Lima (2017) discorrem sobre o estágio como eixo central da formação de professores que pode contribuir no processo de construção de uma identidade profissional, ao permitir o contato com a realidade social, campo de atuação docente. Nessa aproximação, é possível a identificação da complexidade das práticas que os profissionais que nela atuam desenvolvem, bem como o reconhecimento das demandas formativas necessárias à vivência profissional nesse contexto.

Em defesa crítica desse componente curricular e de seus contributos para a construção identitária dos docentes, as autoras defendem o estágio como pesquisa e a pesquisa como estágio com vistas à superação da visão reducionista deste como a hora da prática, apontando para a necessidade de:

[...] Desenvolver atividades que possibilitem o conhecimento, a análise, a reflexão do trabalho docente, das ações docentes, nas instituições, de modo a compreendê-las em sua historicidade, identificar seus resultados, os impasses que apresenta, as dificuldades [...]. (PIMENTA; LIMA, 2017, p. 20).

Quanto ao estágio na pós-graduação, conforme as reflexões trazidas por Costa (2014), é possível destacar que, em sua organização legal, há possibilidades de esse componente curricular contribuir na formação de professores para atuarem na educação superior, apontando especial atenção às formas de organização das instituições, sua concepção no projeto político-pedagógico, de modo que esse processo permita um movimento de aproximação crítica dos pós-graduandos com o exercício da docência universitária.

Outro ponto a ser considerado é o modo como os diferentes sujeitos percebem o papel formativo dos estágios:

Educ. Form., Fortaleza, v. 7, n. 1, e4853, jan./abr. 2022

DOI: https://doi.org/10.25053/redufor.v7i1.4853

https://revistas.uece.br/index.php/redufor/index 
Sabemos que o Estágio é um espaço de pesquisa, formulação da identidade docente e de conhecimento pedagógico. $O$ que falta saber é: até que ponto, coordenadores, professores e alunos dos cursos de pós-graduação percebem o valor formativo desta experiência, como oportunidade de ir além da monitoria e das técnicas de ensino aplicadas em sala de aula? Até que ponto esse é um espaço de questionamento, investigação, sistematização e produção de conhecimentos, decorrentes da reflexão sobre a realidade do ensino/pesquisa na universidade. (PIMENTA; LIMA, 2017, p. 70).

As reflexões trazidas pelas autoras corroboram os apontamentos de Costa (2014, p. 11) acerca da necessidade de reconhecimento da dimensão formativa presente nos estágios para que as instituições avancem em diferentes frentes, como: a "[...] valorização deste componente curricular, traduzida em elementos como o planejamento, a reflexão sobre a prática e a responsabilidade com o processo de construção identitária dos (futuros) docentes universitários".

Levando em consideração as reflexões destacadas pelo conjunto de autores que apontam para os elementos presentes nos estágios e suas possibilidades formativas, seguimos à análise das experiências de pós-graduandos do PPGE da UECE com esse componente de sua formação.

\section{0 estágio de docência nas experiências de pós-graduandos}

Como decorrência da abordagem da pesquisa, buscamos analisar e compreender qualitativamente as experiências de cada sujeito, imbuídas de subjetividades, interesses e condições de vida próprias, em vez de oferecer indicadores objetivos a fim de quantificar ou generalizar os resultados. Extraímos das experiências apresentadas pelos sujeitos elementos que possam colaborar com a compreensão das potencialidades do estágio no processo de construção da identidade profissional de pós-graduandos.

Dessa forma, a técnica de análise de conteúdo, na perspectiva de Bardin (2011), ofereceu elementos importantes para esse processo, para a organização, categorização e inferências. Os resultados seguem apresentados.

\subsection{Breve perfil dos sujeitos da pesquisa}


Os colaboradores da pesquisa estão em processo de formação no âmbito do programa de pós-graduação stricto sensu em Educação da UECE. De acordo com os dados obtidos com o questionário, cinco são do sexo feminino e dois do sexo masculino, sendo todos vinculados ao mestrado. Todos ingressaram na pós-graduação em 2019, mesmo ano em que realizaram suas experiências de estágio de docência.

Quanto à faixa etária, três pós-graduandos têm entre 20 e 25 anos (MB, MC e $M D$ ), um tem entre 26 e 30 anos (MG), dois têm entre 31 e 35 anos (ME e MF) e um tem mais de 46 anos (MA).

No tocante à formação inicial, os sujeitos da pesquisa são oriundos de licenciaturas e bacharelados, sendo, na maioria, de licenciaturas, cursos que habilitam profissionalmente para a docência na educação básica (BRASIL, 1996). Cinco são egressos do curso de Pedagogia (MA, MB, MC, MD e MG), um do curso de Educação Física (ME) e um do curso de Música (MF).

Referente às especializações, quatro pós-graduandos não dispõem dessa titulação (MB, MC, MD e MG). Os que apresentaram título de especialistas são egressos dos seguintes cursos: Ensino da Matemática (MA), Psicomotricidade (ME) e Pesquisa Científica (MF).

Em relação à experiência profissional em docência, os sujeitos apontaram experiências na educação infantil e no ensino fundamental, distribuídos da seguinte forma: MA, nove anos no ensino fundamental I; MB, um ano e seis meses na educação infantil; MD, um ano e quatro meses na educação infantil; ME, dois anos no ensino fundamental I e seis meses no ensino fundamental II; MF, um ano no ensino fundamental II; e MG, seis anos no ensino fundamental.

\subsection{Experiências significativas e constituidoras de aprendizagens}

A partir do questionamento "Você considera que o estágio de docência da pós-graduação contribuiu para o seu processo de aprendizagem da docência universitária? Se sim, comente a experiência e as aprendizagens constituídas", foi realizada uma classificação das experiências dos sujeitos; além disso, foram identificadas as aprendizagens no âmbito da docência no ensino superior, permitindo perceber a 
relevância do estágio no processo de construção da identidade profissional dos pós-graduandos.

No que diz respeito às diferentes experiências apontadas como significativas e constituidoras de aprendizagens, foi destacada por seis pós-graduandos uma visão ampliada do exercício da docência na educação superior, além da oportunidade de atuarem como protagonistas nesse processo. Os excertos a seguir representam essas compreensões:

Acredito que realizar esse estágio com minha professora orientadora em uma disciplina de Pesquisa Educacional foi muito significativo para o meu processo de constituição da aprendizagem da docência. [...] Vivenciei na prática como ajudar pesquisadores iniciantes na elaboração de um projeto de pesquisa; acompanhei desde o início o processo de escrita científica deles; tive a oportunidade também de corrigir esses projetos, ministrar oficinas, sempre com vistas à construção colaborativa do projeto de pesquisa. (MB).

O estágio em docência trouxe uma visão ampliada da docência universitária. Minha experiência se deu numa disciplina que acontecia no primeiro semestre de um curso da área de Saúde: a disciplina denominada Educação e Saúde, refletindo sobre a importância da parceria entre ambas para a promoção da saúde [...]. (MD).

Todas as experiências vividas por mim durante o período do estágio foram significativas, entre as quais as viagens semanais, a convivência mais próxima com minha orientadora e a atuação em sala de aula com pessoas de outra área diferente da minha. Estando eu vinculada a um programa de pós-graduação em Educação, considero de extrema importância ter podido conhecer melhor 0 campo e os profissionais da Pedagogia, a ciência da educação. (MF).

Os trechos apresentados permitem-nos identificar diferentes possibilidades de aproximação com a realidade do ensino superior. Os estágios de docência promovem a aproximação dos pós-graduandos com contextos e situações diversas, como o conhecimento de diferentes disciplinas, áreas do conhecimento, cursos e sujeitos, potencializando a ampliação da visão de mundo e a compreensão do todo do fazer docente.

Segundo Costa (2018), para uma compreensão ampla do trabalho dos professores universitários, é necessário o autorreconhecimento dos profissionais das diferentes áreas como educadores. A partir dessa compreensão, a Educação, como prática social situada; a Pedagogia, como ciência da educação que colabora com a apreensão crítica dos horizontes formativos em suas diferentes dimensões; e a Didática, como parte dessa ciência que se ocupa da reflexão crítica sobre a mediação

Educ. Form., Fortaleza, v. 7, n. 1, e4853, jan./abr. 2022

DOI: https://doi.org/10.25053/redufor.v7i1.4853

https://revistas.uece.br/index.php/redufor/index 
entre os processos de ensino e aprendizagem, tornam-se referências importantes. Estas permitem aos novos professores problematizarem suas próprias experiências e reelaborá-las permanentemente, sem perder de vista os compromissos políticos e pedagógicos nelas presentes.

Outro aspecto destacado pelos pós-graduandos diz respeito ao processo de organização e desenvolvimento do ensino e aprendizagem no âmbito das disciplinas. Este pode ser ilustrado pelos excertos a seguir:

O estágio me fez refletir como se pensa a educação no ensino superior. A necessidade de conhecer o conteúdo como também a mobilização de como ensinar, a partir de uma nova perspectiva, que é a educação de adultos. A aprendizagem como discente é entender o papel docente nesse processo formativo, como também refletir minhas práticas como discente e docente no ensino superior. (MC).

Nessa experiência, eu pude aprender também com o professor responsável da disciplina: desde planejar a disciplina em conjunto e na forma de executar o planejamento também. (ME).

Primeiro, o contato com a elaboração da ementa da disciplina, cuja finalidade era dar aos alunos oportunidades de formação correspondente às suas indagações e necessidades de formação. Segundo, a flexibilidade que devemos desenvolver diante das necessidades dos alunos, realizando durante o planejamento das aulas a retirada ou inclusão de novos temas a serem trabalhados em sala. Terceiro, o docente universitário deve realizar um bom planejamento de suas aulas, estar atento à caminhada da disciplina, para que corresponda e contribua para a formação inicial dos docentes. Por fim, assumir a identidade docente de forma coerente e sensível ao contexto social, cultural e formativo que os alunos apresentam. (MG).

As aprendizagens referem-se à organização do processo de ensino e apontam que, além do conhecimento do conteúdo, também é exigido do professor o conhecimento didático-pedagógico e de sistematização das formas de desenvolver e de avaliar o planejamento. Tais aprendizagens se relacionam a aspectos importantes da identidade docente; sendo a docência uma prática complexa, socialmente produzida, marcada por experiências vivas (OLIVEIRA; ARAÚJO; SILVA, 2021), requer dos professores um conjunto de saberes, bem como que estes adotem uma postura reflexiva e flexível diante do contexto; um olhar atento para a própria prática e para a forma como ocorre o desenvolvimento da disciplina. Assim, compreendemos, conforme mencionam Pimenta e Anastasiou (2008), que não basta o domínio dos conhecimentos específicos de cada área, é necessário saber ensinar, aspecto presente nos saberes didáticos e pedagógicos.

Educ. Form., Fortaleza, v. 7, n. 1, e4853, jan./abr. 2022

DOI: https://doi.org/10.25053/redufor.v7i1.4853

https://revistas.uece.br/index.php/redufor/index 


\title{
5.3 Experiências que limitaram o processo formativo dos estagiários
}

Quando indagados sobre as dificuldades encontradas na realização do estágio, os sujeitos destacaram diferentes aspectos relacionados com a mediação do processo de ensino e aprendizagem, como relação educador e educandos; ausência de conhecimentos sobre os processos de ensinar e aprender, além da falta de conhecimentos sobre os assuntos das disciplinas.

Os relatos a seguir permitem-nos compreender a visão dos sujeitos sobre o tema:

\begin{abstract}
A maior dificuldade é contribuir para que os discentes possam estar estudando, procurando soluções e levantando questionamentos acerca dos conteúdos e da atuação profissional. (MC).

[...] destaco a necessidade de ter mais flexibilidade com os alunos, pois em alguns momentos o planejamento da aula não funciona como o esperado, tendo que ser refeito no desenvolvimento da aula. Diante desse cenário, acabei tendo insegurança. (MG).

[...] as maiores dificuldades foram nos conteúdos que, às vezes, não eram conhecidos e específicos do curso, necessitando de uma leitura mais aprofundada. (MD).
\end{abstract}

A partir dos relatos dos pós-graduandos, reiteramos a compreensão de que a condução do processo de ensino e aprendizagem é uma ação complexa que demanda dos docentes conhecimentos de ordens variadas, dentre os quais estão os conhecimentos específicos da área, contudo apenas o domínio desses conhecimentos não é suficiente. Os conhecimentos da experiência, em diálogo com os conhecimentos pedagógicos, possibilitam o movimento de reflexão sobre as vivências no ensino superior e a construção de estratégias para a superação dos diferentes desafios que se apresentam em sala de aula.

Outro elemento presente nos relatos dos sujeitos está relacionado a problemas no processo de orientação/supervisão nos estágios:

Por conta dos problemas pessoais da minha professora, tive que ministrar aulas sozinha com a turma sem muita orientação prévia do que deveria fazer, me deixando insegura diante da situação. (MA). 
Em alguns momentos, eu ministrei as aulas sozinha, sem a presença da professora. [...] essa foi a maior dificuldade, pois geralmente eu não tinha tempo de planejar essas aulas, uma vez que a professora me comunicava apenas um dia antes. (MB).

Os depoimentos apontam para a necessidade de reconhecimento do estágio de docência como uma etapa formativa, desenvolvida sempre com a presença e a orientação do professor responsável pela disciplina. Destaca-se, assim, a intersubjetividade no processo de aprendizagem dos sujeitos, sendo imprescindível a relação e abertura ao outro (THERRIEN; AZEVEDO; LACERDA, 2017). Nesse sentido, a experiência do estágio pode ser potencializada se desenvolvida mediante um trabalho de supervisão, orientação e reflexão (LIMA; ANDRADE; COSTA, 2020). Sendo assim, para que o estágio contribua para o processo de construção da identidade profissional, na aprendizagem de saberes e posturas necessárias na inserção profissional (PIMENTA; LIMA, 2017), é fundamental um trabalho colaborativo e dialógico entre o(a) pós-graduando(a) e o(a) professor(a) que já é docente de ensino superior.

Os pós-graduandos também foram instigados a responder sobre a percepção dos desafios quanto a ser professor universitário. As respostas apontaram para aspectos diversos, o que nos remete à complexidade da educação e do ensino, expressa nas intenções formativas, diversidade de pensamentos e elementos relacionados à desvalorização do magistério.

As respostas dos mestrandos a seguir apontam para os desafios relacionados ao desenvolvimento das intencionalidades formativas que permeiam o ensino superior. Assim, é destacado o papel desse professor quanto à formação de pessoas e profissionais; nesse sentido, os sujeitos ainda apresentaram suas concepções em torno da formação:

[...] Paralelo a isso tudo, compreender que, assim como o professor da educação básica, ele também é responsável pela formação de pessoas, não só para o mercado de trabalho, mas para também atuarem de forma crítica e participativa na sociedade. Compreender a sua responsabilidade com aqueles que estão sobre os seus cuidados em formação [...]. (MA).

Eu acredito que, em um curso de formação de professores, a maior dificuldade que o professor universitário passa é contribuir na maturidade profissional (principalmente no meu caso, que foram estudantes do primeiro semestre de Pedagogia); [...] façam refletir sobre a sua própria formação como também futura atuação, no intuito que possam ser formados os melhores profissionais possíveis dentro de um determinado tempo histórico. (MC).

Educ. Form., Fortaleza, v. 7, n. 1, e4853, jan./abr. 2022

DOI: https://doi.org/10.25053/redufor.v7i1.4853

https://revistas.uece.br/index.php/redufor/index 
[...] No mais, ministrar aula em âmbito superior considero sempre um desafio; formar professores, formar pessoas é sempre complexo. (ME).

Os fins formativos postos aos docentes do ensino superior permeiam objetivos ligados ao desenvolvimento da ciência e do pensamento reflexivo e à formação de novos profissionais para a inserção na sociedade (BRASIL, 1996). Dessa forma, as compreensões dos sujeitos sobre os desafios vividos pelos docentes que atuam nesse nível de ensino levam-nos a uma reflexão sobre o caráter complexo da docência e sobre sua dimensão política, na qual se faz presente um projeto de sociedade, demandando desse profissional um trabalho consciente, situado e crítico. A docência exige uma tomada de posição que permita concretizar o processo formativo numa perspectiva humana e emancipatória da educação (PIMENTA; LIMA, 2017).

Em outros desafios mencionados, destacam-se elementos como: atribuições e demandas (MA e MD); valorização da educação (ME e MF); diversidade de pensamentos (MB); e flexibilidade no ensino (MG).

Trata-se de uma profissão que requer bastante tempo, pois é permeada de demandas por produtividade, às vezes muitas responsabilidades para além do mundo acadêmico e consequentemente cobranças para dar conta das singularidades dos conteúdos das disciplinas. (MD).

Acredito que o maior desafio do professor de universidades públicas seja o enfrentamento diário com a falta de valorização da educação e falta de investimentos nos cursos de graduação. (MF).

Acredito que o maior desafio é saber lidar com a diversidade de pensamentos e compreender pensamentos divergentes dos seus. (MB).

O maior desafio é a flexibilidade [...], pois acabei compreendendo que há necessidades que vão surgindo no desenvolvimento da disciplina que precisam de ajustes. (MG).

Refletindo sobre as diferentes percepções dos sujeitos quanto aos desafios do professor de ensino superior, podemos entender que, ao experimentar a profissão, o estágio também permite a identificação dos desafios e da complexidade das práticas que são desenvolvidas e, assim, pode propiciar a inserção e a colaboração no seu processo de constituição profissional (PIMENTA; LIMA, 2017), que envolve, além de outros aspectos, o reconhecimento das especificidades que marcam a docência nesse contexto de ensino. 


\section{Considerações finais}

A partir do presente estudo, buscamos compreender as potencialidades do estágio de docência no processo de construção da identidade profissional de pós-graduandos stricto sensu em Educação. Trazemos, a seguir, a síntese das reflexões geradas diante da aproximação com o fenômeno, realizada por meio dos contributos dos sujeitos participantes da pesquisa.

Quanto à formação de professores de ensino superior, o estudo nos permitiu entender que há omissão na legislação educacional brasileira no tocante à formação específica dos professores para o exercício da docência nesse nível de ensino. Em decorrência dessa indefinição, os diferentes profissionais, sejam licenciados ou bacharéis, tornam-se professores universitários sem uma formação específica para a docência universitária, gerando, desse modo, a necessidade de fortalecimento da Pedagogia Universitária como campo de conhecimento voltado para a formação desse profissional.

No contexto de desenvolvimento do estágio, a partir das experiências dos pós-graduandos, ressaltamos inicialmente que, apesar de ser um programa de pós-graduação em Educação, encontramos entre os sujeitos da pesquisa uma variedade de perfis quanto à formação inicial com vinculação a cursos de licenciatura e de bacharelado (Pedagogia, Educação Física e Música). Essa variedade anuncia bases formativas muito diferentes em relação aos saberes da docência, demandando um olhar atento, nem sempre realizado, por parte dos professores que os recebem para os estágios na graduação.

A partir das respostas do grupo em relação às questões postas no questionário, de modo geral, foram destacados, além das aprendizagens, inúmeros desafios relacionados ao desenvolvimento do estágio de docência, à complexidade e às especificidades da docência no ensino superior. Desse modo, é possível entender que se faz necessário fortalecer o processo de construção da identidade docente dos pós-graduandos no espaço do próprio programa, visto que serão os futuros professores universitários. Em vista disso, a partir dos diferentes elementos extraídos das experiências dos sujeitos, podemos apontar que, apesar dos desafios vividos, o estágio contribuiu no processo formativo dos sujeitos, através da aproximação crítica com o 
contexto e o reconhecimento das especificidades que marcam os processos de ensinar e de aprender no âmbito dos diferentes cursos em que se desenvolveram as experiências de estágio.

No desenvolvimento das atividades, foram proporcionadas aprendizagens ligadas aos saberes didático-pedagógicos, imprescindíveis à docência no ensino superior e à concretização das finalidades formativas dos cursos, contribuindo, assim, para o processo de construção da identidade profissional desses sujeitos como professores de ensino superior. No entanto, o conteúdo das respostas dos pós-graduandos revelou a necessidade de maior investimento no teor reflexivo dos estágios, de modo que estes possam ressignificar as experiências docentes e contribuir para o desenvolvimento do campo da Pedagogia Universitária.

\section{Referências}

BARDIN, L. Análise de conteúdo. São Paulo: 70, 2011.

BRASIL. Lei no 9.394, de 20 de dezembro de 1996. Estabelece as Diretrizes e Bases da Educação Nacional. Diário Oficial [da] República Federativa do Brasil, Poder Executivo, Brasília, DF, 21 dez. 1996.

BRASIL. Portaria no 76, de 14 de abril de 2010. Regulamento da Demanda Social. Diário Oficial [da] República Federativa do Brasil, Poder Executivo, Brasília, DF, 19 abr. 2010.

CAVAlCANTE, M. M. D. Pedagogia universitária: um campo de conhecimento em construção. Fortaleza: UECE, 2014.

COSTA, E. A. S. Diálogo pedagógico entre escola e universidade a partir da formação inicial de professores: o caminho e o caminhar da Unilab. 2018. 126 f. Relatório (Pós-Doutorado em Educação) - Universidade de São Paulo, São Paulo, 2018.

COSTA, E. A. S. Formação do professor para a educação superior: contribuições do estágio de docência. Fortaleza: UECE, 2014.

LIMA, I. S. M. S.; ANDRADE, A. I.; COSTA, N. M. V. N. A prática pedagógica na formação inicial de professores em Cabo Verde: perspectivas dos supervisores. Educação \& Formação, Fortaleza, v. 5, n. 1, p. 3-26, 2020. Disponível em: https://revistas.uece.br/index.php/redufor/article/view/1448. Acesso em: 4 abr. 2021.

MELO, G. F. Pedagogia universitária: aprender a profissão, profissionalizar a docência. Curitiba: CRV, 2018. 
NÓVOA, A. Firmar a posição como professor, afirmar a profissão docente. Cadernos de Pesquisa, São Paulo, v. 47, n. 166, p. 1106-1133, 2017.

NÓVOA, A. Os professores e as histórias de sua vida. In: NÓVOA, A. (org.). Vidas de professores. 2. ed. Porto: Porto, 1992. p. 11-30.

OLIVEIRA, S. M. S.; ARAÚJO, F. M. L.; SILVA, C. D. M. A prática como lócus de produção de saberes: vozes de professores sobre formação inicial e práticas escolares cotidianas. Educação \& Formação, Fortaleza, v. 6, n. 1, e2885, 2021. Disponível em: https://revistas.uece.br/index.php/redufor/article/view/2885. Acesso em: 4 abr. 2021.

PIMENTA, S. G. Formação de professores: identidade e saberes da docência. In: PIMENTA, S. G. (org.). Saberes pedagógicos e atividade docente. São Paulo: Cortez, 2005. p. $15-34$.

PIMENTA, S. G.; ANASTASIOU, L. G. C. Docência no ensino superior. São Paulo: Cortez, 2008.

PIMENTA, S. G.; LIMA, M. S. L. Estágio e docência. 8. ed. São Paulo: Cortez, 2017.

PPGE UECE. Conheça o PPGE. Disponível em: http://www.uece.br/ppge/institucional/conheca-o-ppge/. Acesso em: 10 jul. 2019.

THERRIEN, J.; AZEVEDO, M. R. C.; LACERDA, C. R. A racionalidade pedagógica nos processos de mediação à produção de sentidos e de aprendizagem aos saberes. Educação \& Formação, Fortaleza, v. 2, n. 3, p. 186-199, 2017. Disponível em: https://revistas.uece.br/index.php/redufor/article/view/166. Acesso em: 4 abr. 2021.

UECE. Resolução $n^{\circ}$ 821/2011, de 19 de dezembro de 2011. Estabelece normas para o estágio de docência dos cursos de Programas de Pós-Graduação stricto sensu da Universidade Estadual Do Ceará - UECE. Fortaleza: UECE, 2011. Disponível em: http://www.uece.br/ppge/normas-e-formularios/formularios/. Acesso em: 10 jul. 2019.

\footnotetext{
Maria da Cruz Santos Guimarães, Universidade Estadual do Ceará (UECE), Grupo de Estudo Docência no Ensino Superior e na Educação Básica

i (iDhttps://orcid.org/0000-0003-2961-6979

Mestranda em Educação pelo Programa de Pós-Graduação em Educação (PPGE) da UECE. Membro do Grupo de Estudo Docência no Ensino Superior e na Educação Básica (GDESB/UECE).

Contribuição de autoria: Concepção da pesquisa, coleta e análise de dados.

Lattes: http://lattes.cnpq.br/1661898151452418

E-mail: marycguimaraes20@hotmail.com
}

Elisangela André da Silva Costa, Universidade da Integração Internacional da Lusofonia Afro-Brasileira (Unilab), PPGE da UECE

ii iDhttps://orcid.org/0000-0003-0074-1637

Doutora em Educação pela Universidade Federal do Ceará (UFC) e pós-doutora em Educação pela Universidade de São Paulo (USP). Professora adjunta da Unilab. Professora colaboradora no PPGE da

Educ. Form., Fortaleza, v. 7, n. 1, e4853, jan./abr. 2022

DOI: https://doi.org/10.25053/redufor.v7i1.4853

https://revistas.uece.br/index.php/redufor/index 
UECE. Membro dos Grupos de Pesquisas sobre Formação do Educador (Gepefe/USP) e Docência no Ensino Superior e na Educação Básica (GDESB/UECE).

Contribuição de autoria: Supervisão na pesquisa, contribuições na análise de dados, revisão e ampliação do texto.

Lattes: $\underline{\text { http://lattes.cnpq.br/6038313468372950 }}$

E-mail: elisangela.andre@uece.br

Editora responsável: Lia Machado Fiuza Fialho

Pareceristas ad hoc: Márcia Hobold e Andreia da Silva

\section{Como citar este artigo (ABNT):}

GUIMARÃES, Maria da Cruz Santos; COSTA, Elisangela André da Silva. O estágio de docência no processo de construção da identidade profissional de pós-graduandos.

Educ. Form., Fortaleza, v. 7, n. 1, e4853, 2021. Disponível em:

https://revistas.uece.br/index.php/redufor/article/view/4853

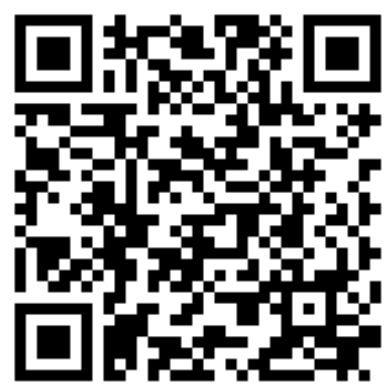

Recebido em 15 de junho de 2021.

Aceito em 14 de agosto de 2021.

Publicado em 1 de janeiro de 2022. 